\title{
GESTÃO DE INOVAÇÃO E DA QUALIDADE NA PRESTAÇÃO DE SERVIÇOS
}

\section{MANAGEMENT OF INNOVATION AND QUALITY IN THE PROVISION OF SERVICES}

\author{
Djair Picchiai \\ José Tartaglione \\ Cristina Nogueira \\ Marília Ayres
}

\section{RESUMO}

Este artigo trata da gestão operacional e estratégica de inovação e de qualidade nas micro e pequenas empresas (MPEs) prestadoras de serviços de diagnósticos em saúde, como laboratórios de análises clínicas, clínicas de radiologia e clínicas de reabilitação localizadas nas cidades de São Paulo, Cotia, Osasco e Campo Limpo Paulista. A pesquisa realizada teve caráter qualitativo e quantitativo, com a aplicação de um questionário de escala Likert aos gestores e colaboradores. Os pesquisadores constataram que, dentro da amostra estudada: os gestores passavam um mínimo de inovação que era bem executado pelos colaboradores, mesmo sem possuírem função de gestão; os executivos definiam um plano de qualidade, e os colaboradores que não possuíam função de gestão executavam o plano; na percepção dos gestores, as organizações não elaboravam nem definiam um plano de inovação; e os gestores como líderes apresentavam dificuldade em desenvolver conhecimentos sobre gestão operacional e visão estratégica de gestão de inovação e de qualidade das MPEs.

PALAVRAS-CHAVE: Inovação. Controle de Qualidade. Serviços. Operações.

\begin{abstract}
This article deals with the operational and strategic management of innovation and quality in micro and small enterprises (MSEs) providing health diagnostic services, such as clinical analysis laboratories, radiology clinics and rehabilitation clinics located in the cities of São Paulo, Cotia, Osasco and Campo Limpo Paulista. The research was qualitative and quantitative, with the application of a Likert scale questionnaire to managers and employees. The researchers found that, within the sample studied: managers passed a minimum of innovation that was well executed by employees, even without having a management function; executives defined a quality plan, and employees who did not have a management function executed the plan; in the perception of managers, organizations did not elaborate or define an innovation plan;
\end{abstract}


and managers as leaders had difficulty developing operational management knowledge and strategic vision for innovation and quality management of MSEs.

KEYWORDS: Innovation. Quality control. Services. Operations.

\section{INTRODUÇÃO}

As mudanças constantes que ocorrem nas esferas sociais, políticas, econômicas e tecnológicas, têm gerado grandes desafios para as organizações. A inovação e a gestão da qualidade, neste contexto, passam a ser consideradas relevantes para a sobrevivência destas organizações. Com relação à inovação, já dizia Schumpeter na década de 1950, que os empresários, ao fazerem uso deste recurso, seja pela criação de um produto, serviço ou de um processo para produzi-lo, poderiam obter vantagem competitiva (Schumpeter, 1950).

Tal afirmação é corroborada por estudos mais recentes, a exemplo de Davila, Epstein e Shelton (2007, p.23) que afirmam que “(...) o único fator realmente capaz de garantir o futuro de qualquer empresa é sua capacidade de inovar melhor e de forma mais contínua, por mais tempo que as concorrentes". Pohlmann (2005) destaca que a inovação é considerada um importante fator de competitividade econômica, enquanto Rosenbusch, Brinckmann e Bausch (2011) complementam ao dizer que é por meio da inovação que as organizações conseguirão progredir.

No que diz respeito à gestão da qualidade, a orientação operacional e estratégica das empresas voltada para os clientes é considerada um determinante. Autores como Fuentes, Montes e Fernandez (2006), Han, Chen e Ebrahimpour (2007), e Lenka e Suar (2008) afirmam que o principal foco da gestão da qualidade é atender às demandas dos clientes. Fernandes, Lourenço e Silva (2011) complementam o tema ao alegar que a gestão da qualidade prevê a adoção de uma estratégia capaz de envolver todos os colaboradores na busca de uma sinergia operacional.

Grande parte das micro e pequenas empresas (MPEs) da área de saúde, muitas delas provenientes de estrutura familiar, iniciam suas atividades geridas pelos seus proprietários, que são especialistas técnicos. Neste contexto, a crescente preocupação com racionalização de custos, consolidação de diferentes tipos de 
análise, melhoria na gestão, nos fluxos de trabalho, e na qualidade dos processos levou estas empresas a buscarem métodos de gestão mais voltados à inovação, resultando na necessidade do desenvolvimento de novas competências e capacidades gerenciais e administrativas, que compõem as novas funções administrativas (SOLLA; CHIORO, 2008).

A evolução nos métodos de gestão nas MPEs, incluindo o foco da inovação torna-se, portanto, uma questão de sobrevivência, e nos leva ao objetivo principal deste estudo que pode ser formulado pela questão: Como a gestão da qualidade e a gestão da inovação são praticadas nas MPEs do setor de saúde?

Para responder esta questão foi realizado um estudo qualitativo, em uma amostra de vinte empresas localizadas na região sul da cidade de São Paulo, Osasco, Cotia e Campo Limpo Paulista, por meio de entrevistas estruturadas com questionário fundamentado em uma escala Likert, com diferencial semântico de cinco colunas que mede opiniões e atitudes.

\section{DESENVOLVIMENTO}

\section{Gestão da Inovação}

Inovação é um tema que vem sendo referenciado a várias décadas, a exemplo de Schumpeter (1934) que trouxe em sua obra uma visão que relaciona a inovação como fator determinante no processo dinâmico da economia. Essa visão criou escola, os Neoshumpeterianos, que consideram de um modo geral que a inovação é o único caminho de sobrevivência nos mercados, tanto de processos quanto de produtos novos, cada vez mais competitivos (TAVARES; KRETZER; MEDEIROS, 2005).

Existem vários conceitos relacionados à inovação, e em todos os casos o autor condiciona competitividade e sucesso da organização às mudanças provenientes dos processos de inovação, e ainda ressalta a necessidade de uma gestão adequada para que os resultados esperados ocorram. Como exemplo, Serafim (2011) relaciona a inovação com uma estratégia competitiva muito eficiente para o desempenho organizacional, Tidd e Bessant (2015) afirmam que inovação é um processo de 
transformação de ideias com o objetivo de capturar valor para a empresa, e Tigre (2014) considera a inovação uma poderosa arma competitiva pelos empreendedores.

As mudanças provenientes da inovação podem vir por meio de novos produtos ou serviços, novos modelos de negócios e mercados, novas formas de gestão, novas tecnologias ou mesmo novos canais de distribuição. O Manual de Oslo (2005) detalha este entendimento quando classifica a inovação em quatro tipos: 1) inovação de produtos (bem ou serviço), seja criando algo novo ou melhorando algo já existente; 2) inovação de um processo, a exemplo de um novo método de produção ou distribuição; 3) inovação de marketing relacionado com as formas de se apresentar ou comercializar um produto ou serviço; e 4) inovação organizacional que envolve mudanças nas práticas do negócio, novos modelos de negócio ou novos métodos organizacionais.

Através dessas dimensões pode-se perceber que não se trata de ações isoladas, mas sim de um conjunto de ações encadeadas em processos e rotinas que, por sua vez, deve ser gerenciado como tal, promovendo na empresa a capacidade inovadora, a habilidade de organizar os processos e a integração destes com a tecnologia e o mercado (TIDD; BESSANT, 2015; IACONO; NAGANO, 2014). Kuczmarski (1998) já dizia, reforçando as ações relacionadas à gestão, que a inovação deve estar em sintonia com a estratégia organizacional, com os ambientes interno e externo, através da identificação de competências essenciais e oportunidades, da capacidade em manter uma cultura e projetos inovadores e pela criação de rotinas que incorporem a consciência inovadora ao dia a dia organizacional. Sobre este ponto, Tidd e Bessant (2015) complementam que a gestão adequada envolve implantar rotinas eficazes para lidar com os desafios que envolvem a inovação.

\section{Inovação em Serviços}

Quando se fala de serviços, pressupõe-se a necessidade da presença do cliente ou de um bem de sua propriedade, conforme afirma Gianesi e Correa (2009). Essa proximidade entre o fornecedor e o usuário final faz com que o comprometimento de todos os envolvidos seja fundamental para o sucesso, pois os profissionais são 
elos entre uma ação bem-sucedida ou não. Sobre isto, Espuny (2008) acrescenta que as pessoas conhecem a organização não somente por meio de suas instalações físicas, mas também pelo contato com seus funcionários.

$\mathrm{Na}$ década de 1980, falar de inovação na área de serviços resumia-se ao acompanhamento de processos de difusão das inovações tecnológicas (BARRAS, 1990). Desde então, novos estudos apareceram com o intuito de identificar pontos comuns para o desenvolvimento de um enfoque que englobasse bens e serviços, ao mesmo tempo em que não deixasse de lado suas especificidades (GALLOUJ, 2007).

Tidd e Bessant (2015) corroboram com Gallouj (2007) quando afirmam que a gestão da inovação não se restringe apenas a produtos fabricados, mas também a serviços, e acrescentam que o resultado na gestão da inovação depende em grande parte da capacidade de encontrar novas maneiras de fazer as coisas, bem como de se obter vantagens estratégicas. $\mathrm{Na}$ área da saúde, as intensas mudanças provocadas por um mundo globalizado, dentre elas novas regulamentações técnicas e governamentais, códigos do consumidor, concorrências, e fusões que criaram grandes organizações prestadoras de serviços levaram tais organizações a promoverem algumas transformações em seus negócios (FILHO, 2010).

$O$ desenvolvimento de competências e capacidades gerenciais e administrativas com o objetivo de construir novas relações com o público, pautadas pela transparência e garantia das necessidades e interesses coletivos passa a ser necessário (SOLLA; CHIORO, 2008). Por outro lado, o que se observa na área de saúde são profissionais com atribuições de liderança em organizações prestadoras de serviços recebendo apenas formação técnica; ou seja, que os capacita para diagnósticos, monitorização, prevenção e controle da saúde. De modo geral, tais profissionais possuem pouco conhecimento sobre gestão (SEKI et al., 2003).

Bossuyt et al. (2007) complementa que, embora as técnicas antigas de gestão tenham espaço em algumas organizações prestadoras de serviços na área de saúde, as preocupações crescentes, decorrentes de mudanças ocorridas nos ambientes internos e externos, seja no aumento do número de concorrentes, na necessidade de redução de custos, no aumento do volume e complexidade das solicitações apresentadas pelo cliente, têm levado tais empresas a procurarem novas soluções na área da gestão da inovação. Assim, a busca por conhecimento sobre gestão pelos 
profissionais da área de saúde, destacados por Seki et al. (2003), pode ser melhor definido quando Blumenthal (1997) destaca que tais profissionais devem desenvolver e praticar a gestão da inovação.

\section{Gestão da qualidade X Inovação}

Os conceitos de qualidade sofreram inúmeras modificações e continuam evoluindo, provocando mudanças de práticas, responsabilidades e prioridades em torno de si. Na década de 1980, vários conceitos relacionados à qualidade foram introduzidos no mercado. Gryna, Juran e Seder (1962) afirmaram que qualidade é adequação do produto ou serviço ao uso, ou seja, à necessidade do consumidor, mantendo coerência com o conceito defendido por Ishikawa (1986) que defende que qualidade é a rápida percepção e satisfação das necessidades do mercado, além de garantir a homogeneidade dos resultados dos processos.

Esta visão de Ishikawa (1986) dá ênfase à necessidade de uma malha de relacionamento interno e externo na organização, que possibilite rápido diagnóstico e avaliação de satisfação das necessidades dos consumidores, levando à reformulação dos processos continuamente, para que se possa controlar a qualidade em todas as suas manifestações.

Segundo Davel e Melo (2005), a preocupação com a qualidade surge como forma de estabelecer diferenciais e agregar valor competitivo à organização. As empresas prestadoras de serviços na área da saúde, com suas peculiaridades, buscam esses diferenciais. Observam-se nelas serviços estruturados de Call Center, maior disponibilidade e atenção às demandas apresentadas por seus clientes e atendimento centralizado para marcação de exames de diagnósticos. De acordo com Harvey (1998), quando mais próximo for o contato com o cliente, mais complexo será a satisfação de suas necessidades, e menos importantes tornam-se as noções de gestão da qualidade procedente do setor manufatureiro.

Com relação à percepção de gestão da qualidade praticada nas empresas, Deming (1990) afirma que algumas características da qualidade em serviços são tão fáceis de quantificar e de medir quanto características da qualidade em serviços de um produto manufaturado. Como exemplo de características importantes e fáceis de 
medir dos serviços, o autor cita exatidão da documentação, velocidade de expedição, credibilidade do tempo de entrega, cuidado no manuseio, entre outras.

Outra avaliação a ser feita na gestão de qualidade inclui comparar as expectativas que o cliente tem a respeito do serviço e a sua percepção sobre a qualidade do serviço prestado. Esta avaliação diz respeito à expectativa prévia e à percepção formada durante e após a prestação do serviço; ou seja, compara-se o serviço esperado com o serviço percebido (PASQUALI, 2002).

Donabedian (1978) afirma que a avaliação dos serviços comporta duas dimensões: o desempenho técnico; ou seja, a aplicação do conhecimento e da tecnologia médica para maximizar os benefícios e minimizar os riscos, de acordo com as preferências de cada paciente; e o relacionamento pessoal com o paciente, para satisfazer os preceitos éticos, as normas sociais e as legítimas expectativas e necessidades dos pacientes. A partir da interação entre o cliente e o médico, existe um processo complexo, que vai desde componentes comportamentais até componentes técnicos muito específicos.

Segundo Bonato (2011), criar um ambiente de trabalho que estimule o compartilhamento de conhecimentos, em que as relações pessoais se manifestam gerando novos conhecimentos, o desenvolvimento de novas competências coloca-se como desafio para a organização focada na gestão das pessoas e preocupada com a qualidade. Organizações vencedoras são aquelas que criam alternativas com maior rapidez, avançando, melhorando, identificando suas fragilidades e estabelecendo oportunidades para criar mecanismos inovadores no cotidiano. Outro aspecto que merece destaque é a definição e identificação da concorrência, estabelecendo formas para identificá-las e criar mecanismos para lidar com ela (BONATO, 2011).

A Qualidade Total surge como ferramenta de apoio para tratar esta realidade. Assume diferentes significados: qualidade de trabalho, serviço, informação, processo, estrutura e pessoas. Implica na satisfação das expectativas e necessidades dos clientes por meio de uma gestão científica dos processos, baseada em fatos e dados, voltada para a correção e prevenção de erros. Deve ser baseada na manutenção e melhoria dos padrões de desempenho atuais, com produtos e serviços melhores e mais competitivos, na participação e envolvimento dos membros da organização, 
considerando aspectos éticos que envolvem a prestação dos serviços de saúde (BONATO, 2011).

Ainda segundo Bonato (2011), as ações voltadas ao desenvolvimento do potencial humano mostram-se presentes nos planos e ações das organizações, que atuam no segmento de saúde, independentemente do seu porte. As ações dos gestores em saúde contêm a representação social do conceito de "trabalho" e "qualidade", que estabelece a vinculação do fazer com a percepção e com a verdade tomada pela liderança como direcionadora de seus planos de trabalho.

Essas ações, com frequência, parecem ser mais dirigidas intuitivamente do que embasadas em conhecimento construído, alinhando a teoria e a prática. Consolidar e fortalecer o processo de gestão da qualidade significa aproximar as áreas técnicas e estratégicas dentro das instituições. Os serviços de saúde, quaisquer que sejam eles, devem deixar de ser entendidos apenas como locais de promoção, prevenção e assistência aos pacientes, mas devem ser encarados como organizações que necessitam de gerenciamento e foco no cliente (BONATO, 2011).

É importante atribuir ao usuário do serviço de saúde papel relevante na montagem e funcionamento desse serviço, portanto, é fundamental buscar conhecer e entender o seu modo de perceber o atendimento prestado. Não há dúvidas de que o funcionamento dos serviços de saúde acaba por se organizar para atender às necessidades exclusivas dos profissionais e das instituições que representam, segundo Bonato (2011). E por esse motivo, é também importante conhecer a percepção dos profissionais que trabalham nessa área.

\section{MÉTODO DA PESQUISA E ANÁLISE DOS DADOS}

Nesta pesquisa, adotou-se o método misto, ou seja, qualitativa e quantitativa, de acordo com Creswell (2007). Na coleta de dados desse estudo, aplicou-se um questionário do tipo Likert, com uma escala de cinco pontos com as classificações: "concordo totalmente - CT"; "concordo em parte - C", "neutro ou indiferente - I", "discordo em parte - D" e "discordo totalmente - DT".

O questionário aplicado foi composto de 26 perguntas (proposições): quatro para determinar o perfil dos entrevistados, que são gestores de empresas prestadoras 
de serviços na área de saúde, e 22 para avaliar a percepção destes gestores, conforme as respostas fornecidas pelo método de escala Likert.

Foram 12 perguntas para determinação da percepção dos gestores sobre a prática de gestão estratégica e de gestão operacional de inovação, sendo seis para determinação da gestão operacional de inovação, praticada pelos colaboradores que não têm função de gestão das empresas pesquisadas e seis para determinação da gestão estratégica de inovação, praticada pelos gestores das empresas pesquisadas; dez perguntas para determinação da percepção dos gestores sobre a prática de gestão estratégica e de gestão operacional de qualidade nas empresas pesquisadas, sendo quatro para determinação da gestão operacional de qualidade, praticada pelos colaboradores que não têm função de gestão das empresas pesquisadas e seis para determinação da gestão estratégica de qualidade, praticada pelos gestores das empresas pesquisadas.

As 22 proposições foram agrupadas de acordo com os grupos considerados pelos autores: IC refere-se às proposições sobre a percepção dos gestores de gestão operacional de inovação, praticada pelos colaboradores que não têm função de gestão dessas empresas (seis proposições); IE refere-se às proposições sobre a percepção dos gestores de gestão estratégica de inovação, praticada pelos gestores dessas empresas (seis proposições); QC refere-se às proposições sobre a percepção dos gestores de gestão operacional de qualidade, praticada pelos colaboradores que não têm função de gestão dessas empresas (quatro proposições); QE refere-se às proposições sobre a percepção dos gestores de gestão estratégica de qualidade, praticada pelos gestores dessas empresas (seis proposições), conforme Tabela 1. 
Tabela 1 - Proposições para as gestões de inovação e qualidade

\begin{tabular}{|c|c|}
\hline \multicolumn{2}{|r|}{ Proposições } \\
\hline Código & Inovação \\
\hline IC1 & Os colaboradores possuem suas atividades bem definidas e estabelecidas por normas. \\
\hline IC2 & $\begin{array}{l}\text { Os colaboradores têm a necessidade de compreender quais são os exames e diagnóstivos oferecidos } \\
\text { pela empresa para os clientes. }\end{array}$ \\
\hline IE1 & A empresa possui instalações e equipamentos modernos para oferecer aos seus clientes. \\
\hline IC3 & Os colaboradores expõem com clareza para os clientes os objetivos e as diretrizes da empresa. \\
\hline IC4 & Os colaboradores precisam ter consciência de seu papel junto à clientela. \\
\hline IE2 & A empresa promove capacitação para desenvolvimento técnico dos profissionais. \\
\hline IE3 & A empresa sente a necessidade de promover capacitação para desenvolvimento dos gestores. \\
\hline IE4 & $\begin{array}{l}\text { A empresa executa mudanças necessárias na estrutura para estimular novas ideias, facilitando a tomada } \\
\text { de decisão. }\end{array}$ \\
\hline IE5 & A empresa trabalha próximo dos clientes na exploração e desenvolvimento de novos conceitos e serviços. \\
\hline IC5 & Os colaboradores participam com sugestões ou ideias para melhorias dos produtos ou processos \\
\hline IC6 & Os colaboradores se sentem a vontade para falar, criticar, sugerir, trocar informações \\
\hline IE6 & $\begin{array}{l}\text { Na sua empresa comparam-se sistematicamente sues produtos e serviços com de outras empresas do } \\
\text { ramo. }\end{array}$ \\
\hline Código & Qualidade \\
\hline QC1 & Na sua empresa os colaboradores se empenham em tratar bem os cliente. \\
\hline QC2 & Os clientes se sentem satisfeitos e confiantes no trabalho dos colaboradores da sua empresa. \\
\hline QC3 & $\begin{array}{l}\text { Na sua empresa os colaboradores têm um pensamento único, que se está trabalhando com vidas } \\
\text { humanas e isto requer antes de tudo muita calma, profissionalismo e o máximo de confiança dos clientes. }\end{array}$ \\
\hline QC4 & Na sua empresa os colaboradores prestam atenção para que os clientes sejam bem tratados. \\
\hline QE1 & $\begin{array}{l}\text { A sua empresa sente a necessidade de se empenhar em fazer os colaboradores entenderem as } \\
\text { necessidades dos clientes. }\end{array}$ \\
\hline QE2 & $\begin{array}{l}\text { A sua empresa se empenha em fazer os colaboradores honrarem os compromissos assumidos com o } \\
\text { cliente. }\end{array}$ \\
\hline QE3 & A sua empresa está falando a verdade quando diz que o cliente está em primeiro lugar. \\
\hline QE4 & $\begin{array}{l}\text { Os clientes estão satisfeitos com as condições físicas e ambientais da sua empresa (temperatura, } \\
\text { higiene, ruído, mobiliário, sanitários). }\end{array}$ \\
\hline QE5 & A sua empresa faz intervenções pontuais no dia a dia para resolver questões junto aos clientes. \\
\hline QE6 & $\begin{array}{l}\text { a sua empresa realiza constantemente pesquisa, junto aos clientes finais e revendedores para conhecer a } \\
\text { qualidade dos seus produtos e serviços. }\end{array}$ \\
\hline
\end{tabular}

Fonte: Elaborada pelos autores

As proposições foram submetidas a um teste-piloto com especialistas da área de prestação de serviços em saúde, com o objetivo de esclarecer se eram plenamente compreensíveis. Para tal, foram apresentadas a três gerentes de laboratórios de análises clínicas e a três gerentes de empresas de diagnósticos. Após o teste-piloto, algumas proposições foram ajustadas na redação para serem mais compreensíveis: cinco proposições foram transformadas em negativas, para valorizar a discordância com vistas a reduzir o viés da resposta positiva ou, como diz Baquero (1974), para 
evitar qualquer tendência ao estereótipo (proposições marcadas com asterisco*) (Tabela 2).

\section{Tabela 2 - Proposições ajustadas em função do teste-piloto}

\begin{tabular}{|c|c|}
\hline $\begin{array}{l}\mathrm{P} \text { (código da } \\
\text { proposição) }\end{array}$ & Proposição \\
\hline IC1 & Na sua empresa os colaboradores possuem suas atividades bem definidas e estabelecidas por normas. \\
\hline IC2 * & $\begin{array}{l}\text { Na sua empresa os colaboradores não têm a necessidade de compreender quais são os exames e } \\
\text { diagnóstivos oferecidos pela empresa para os clientes. }\end{array}$ \\
\hline IC3 & $\begin{array}{l}\text { Na sua empresa os colaboradores expõem com clareza para os clientes os objetivos e as diretrizes da } \\
\text { empresa. }\end{array}$ \\
\hline IC4 * & Na sua empresa os colaboradores não precisam ter consciência de seu papel junto à clientela. \\
\hline IE1 & A sua empresa possui instalações e equipamentos modernos para oferecer aos seus clientes. \\
\hline IE2 & A sua empresa promove capacitação para desenvolvimento técnico dos profissionais. \\
\hline IE3 * & A sua empresa não sente a necessidade de promover capacitação para desenvolvimento dos gestores. \\
\hline IE4 & $\begin{array}{l}\text { A sua empresa executa mudanças necessárias na estrutura para estimular novas ideias, facilitando a } \\
\text { tomada de decisão. }\end{array}$ \\
\hline IE5 & $\begin{array}{l}\text { A sua empresa trabalha próximo dos clientes na exploração e desenvolvimento de novos conceitos e } \\
\text { serviços. }\end{array}$ \\
\hline IC5 * & $\begin{array}{l}\text { Na sua empresa os colaboradores não participam com sugestões ou ideias para melhorias dos produtos } \\
\text { ou processos }\end{array}$ \\
\hline IC6 & Na sua empresa os colaboradores se setem a vontade para falar, criticar, sugerir, trocar informações. \\
\hline IE6 & $\begin{array}{l}\text { Na sua empresa comparam-se sistematicamente sues produtos e serviços com de outras empresas do } \\
\text { ramo. }\end{array}$ \\
\hline QC1 & Na sua empresa os colaboradores se empenham em tratar bem os cliente. \\
\hline QC2 & Os clientes se sentem satisfeitos e confiantes no trabalho dos colaboradores da sua empresa. \\
\hline QC3 & $\begin{array}{l}\text { Na sua empresa os colaboradores têm um pensamento único, que se está trabalhando com vidas } \\
\text { humanas e isto requer antes de tudo muita calma, profissionalismo e o máximo de confiança dos clientes. }\end{array}$ \\
\hline QC4 & Na sua empresa os colaboradores prestam atenção para que os clientes sejam bem tratados. \\
\hline QE1 * & $\begin{array}{l}\text { A sua empresa não sente a necessidade de se empenhar em fazer os colaboradores entenderem as } \\
\text { necessidades dos clientes. }\end{array}$ \\
\hline QE2 & $\begin{array}{l}\text { A sua empresa se empenha em fazer os colaboradores honrarem os compromissos assumidos com o } \\
\text { cliente. }\end{array}$ \\
\hline QE3 & A sua empresa está falando a verdade quando diz que o cliente está em primeiro lugar. \\
\hline QE4 & $\begin{array}{l}\text { Os clientes estão satisfeitos com as condições físicas e ambientais da sua empresa (temperatura, } \\
\text { higiene, ruído, mobiliário, sanitários). }\end{array}$ \\
\hline QE5 & A sua empresa faz intervenções pontuais no dia a dia para resolver questões junto aos clientes. \\
\hline QE6 & $\begin{array}{l}\text { a sua empresa realiza constantemente pesquisa, junto aos clientes finais e revendedores para conhecer a } \\
\text { qualidade dos seus produtos e serviços. }\end{array}$ \\
\hline
\end{tabular}

Fonte: Elaborada pelos autores após teste piloto

Executou-se um procedimento para análise da consistência dos itens seguindo o que determina Baquero (1974). Primeiro selecionou-se dez empresas prestadoras de serviços na área de saúde, localizadas nos bairros do Itaim Bibi, Jardins, Moema e Brooklin, na cidade de São Paulo; e dez empresas prestadoras de serviços na área de saúde, localizadas nas cidades de Cotia, Osasco e Campo Limpo Paulista. O 


\section{Gestão em Saúde}

questionário ajustado (Tabela 2) foi aplicado aos respondentes e os resultados foram compilados conforme Tabela 3.

\section{Tabela 3 - Dados coletados para consistência interna dos itens}

\begin{tabular}{|c|c|c|c|c|c|c|c|c|c|c|c|c|c|c|c|c|c|c|c|c|c|c|c|}
\hline $\mathbf{N I}$ & \begin{tabular}{|l|} 
R12 \\
\end{tabular} & \begin{tabular}{|l|} 
R14 \\
\end{tabular} & R3 & \begin{tabular}{l|l}
$\mathbf{R} 8$ \\
\end{tabular} & R5 & R1 & $\mathbf{R 4}$ & R13 & \begin{tabular}{|l|} 
R19 \\
\end{tabular} & \begin{tabular}{|l|} 
R18 \\
\end{tabular} & SG1 & $\mathbf{R} 2$ & R6 & $\mathbf{R 7}$ & $\mathbf{R 9}$ & \begin{tabular}{|l|} 
R10 \\
\end{tabular} & \begin{tabular}{|l|} 
R11 \\
\end{tabular} & R15 & \begin{tabular}{|l|} 
R16 \\
\end{tabular} & \begin{tabular}{|l|} 
R17 \\
\end{tabular} & \begin{tabular}{|l|}
$\mathbf{R} 20$ \\
\end{tabular} & SG2 & $\mathrm{D} / 10$ \\
\hline IC1 & 2 & 4 & 3 & 2 & 2 & 4 & 4 & 4 & 3 & 4 & 32 & 4 & 4 & 5 & 5 & 4 & 4 & 4 & 5 & 4 & 4 & 43 & -1.1 \\
\hline IC2 * & 4 & 2 & 3 & 2 & 4 & 5 & 5 & 4 & 4 & 3 & 36 & 4 & 5 & 5 & 4 & 4 & 5 & 5 & 5 & 4 & 5 & 46 & -1.0 \\
\hline IE1 & 3 & 4 & 4 & 4 & 4 & 4 & 4 & 4 & 5 & 4 & 40 & 4 & 5 & 5 & 5 & 4 & 4 & 5 & 5 & 5 & 4 & 46 & -0.6 \\
\hline IC3 & 2 & 3 & 2 & 2 & 2 & 4 & 4 & 3 & 4 & 2 & 28 & 4 & 5 & 4 & 5 & 4 & 4 & 5 & 5 & 4 & 4 & 43 & -1.5 \\
\hline IC4 $^{*}$ & 4 & 4 & 4 & 4 & 4 & 4 & 4 & 3 & 4 & 4 & 39 & 5 & 5 & 4 & 5 & 5 & 4 & 5 & 5 & 4 & 4 & 46 & -0.7 \\
\hline IE2 & 2 & 2 & 4 & 2 & 2 & 4 & 4 & 4 & 4 & 4 & 32 & 2 & 2 & 4 & 4 & 4 & 4 & 4 & 4 & 4 & 4 & 36 & -0.4 \\
\hline $\mathrm{IE}^{*}$ & 2 & 2 & 3 & 2 & 2 & 4 & 4 & 4 & 4 & 2 & 29 & 4 & 4 & 2 & 4 & 4 & 4 & 5 & 4 & 4 & 4 & 39 & -1.0 \\
\hline IE4 & 2 & 2 & 2 & 3 & 3 & 2 & 2 & 3 & 4 & 3 & 26 & 4 & 2 & 4 & 4 & 4 & 3 & 4 & 4 & 4 & 5 & 38 & -1.2 \\
\hline IES & 5 & 4 & 4 & 4 & 4 & 4 & 4 & 4 & 4 & 4 & 41 & 5 & 5 & 4 & 5 & 4 & 4 & 4 & 5 & 3 & 4 & 43 & -0.2 \\
\hline IC5 * & 3 & 5 & 4 & 5 & 4 & 3 & 3 & 4 & 4 & 4 & 39 & 4 & 5 & 4 & 4 & 5 & 4 & 5 & 4 & 5 & 4 & 44 & -0.5 \\
\hline IC6 & 1 & 2 & 4 & 2 & 2 & 2 & 2 & 2 & 3 & 5 & 25 & 4 & 5 & 4 & 4 & 2 & 4 & 1 & 4 & 4 & 4 & 36 & -1.1 \\
\hline QC1 & 2 & 4 & 3 & 4 & 5 & 4 & 4 & 4 & 4 & 3 & 37 & 5 & 4 & 5 & 5 & 4 & 5 & 5 & 5 & 4 & 5 & 47 & -1.0 \\
\hline QC2 & 4 & 4 & 4 & 4 & 5 & 4 & 4 & 4 & 5 & 4 & 42 & 5 & 4 & 5 & 5 & 4 & 5 & 5 & 5 & 5 & 5 & 48 & -0.6 \\
\hline QE1* $^{*}$ & 3 & 4 & 4 & 4 & 4 & 5 & 5 & 4 & 4 & 5 & 42 & 4 & 4 & 5 & 5 & 4 & 5 & 4 & 5 & 4 & 5 & 45 & -0.3 \\
\hline QE2 & 4 & 4 & 4 & 4 & 5 & 5 & 5 & 4 & 4 & 5 & 44 & 5 & 4 & 5 & 5 & 4 & 5 & 4 & 4 & 4 & 5 & 45 & -0.1 \\
\hline QC3 & 4 & 4 & 4 & 4 & 5 & 3 & 3 & 3 & 4 & 5 & 39 & 5 & 5 & 5 & 5 & 5 & 5 & 5 & 5 & 5 & 5 & 50 & -1.1 \\
\hline QE3 & 2 & 2 & 2 & 4 & 4 & 4 & 4 & 4 & 4 & 5 & 35 & 4 & 5 & 2 & 5 & 5 & 5 & 5 & 4 & 5 & 5 & 45 & -1.0 \\
\hline QC4 & 2 & 3 & 4 & 5 & 4 & 2 & 2 & 4 & 4 & 5 & 35 & 4 & 5 & 4 & 4 & 5 & 5 & 4 & 4 & 5 & 5 & 45 & -1.0 \\
\hline QE4 & 3 & 4 & 4 & 4 & 5 & 4 & 4 & 4 & 4 & 4 & 40 & 4 & 4 & 4 & 5 & 5 & 4 & 5 & 4 & 4 & 5 & 44 & -0.4 \\
\hline QE5 & 4 & 4 & 4 & 4 & 3 & 5 & 5 & 5 & 3 & 5 & 42 & 5 & 4 & 4 & 5 & 3 & 4 & 4 & 4 & 4 & 4 & 41 & 0.1 \\
\hline QE6 & 3 & 4 & 3 & 4 & 4 & 3 & 3 & 4 & 4 & 3 & 35 & 4 & 4 & 5 & 4 & 5 & 5 & 4 & 5 & 5 & 5 & 46 & -1.1 \\
\hline
\end{tabular}

Fonte: Dados da pesquisa

Legenda: N1: número interno da proposição. O sinal * indica que a mesma proposição invertida; Ri: número do respondente. SG1: soma dos pontos obtidos pela proposição no grupo G1; SG2: soma dos pontos obtidos pela proposição no grupo G2. D/10: valor de (SG1-SG2)/10.

As respostas foram analisadas e tabuladas atribuindo-se os números correspondentes à posição na coluna: $\mathrm{DT}=1 ; \mathrm{D}=2 ; \mathrm{I}=3 ; \mathrm{C}=4 \mathrm{e} \mathrm{CT}=5$. As colunas foram separadas em dois grupos (G1 e G2), por conveniência de respostas. Os respondentes de R1 a R10 localizavam-se na cidade de São Paulo, de R11 a R14 localizavam-se em Cotia, de R15 a R19 em Osasco, e R20 em Campo Limpo Paulista. Cada grupo de dez respondentes foi dividido em dois grandes grupos: o grupo G1, 
composto pelos respondentes $\mathrm{R} 12, \mathrm{R} 14, \mathrm{R} 3, \mathrm{R} 8, \mathrm{R} 5, \mathrm{R} 1, \mathrm{R} 4, \mathrm{R} 13, \mathrm{R} 19$ e $\mathrm{R} 18$, e o G2, composto pelos respondentes R2, R6, R7, R9, R10, R11, R15, R16, R17 e R20, e então, foi calculada a soma obtida para cada proposição, como mostra a Tabela 3.

A coluna $\mathrm{D} / 10$ da Tabela 3 , indica o poder discriminatório da proposição, segundo Baquero (1974). Quanto maior o quociente maior será a validade do item. O que importa é o valor absoluto do item, que deve ser superior a um; isto é, desprezando-se o sinal, são válidas as proposições com $|\mathrm{D} / 10|>1$. Nesta pesquisa, foram consideradas apenas as proposições que obtiveram $|\mathrm{D} / 10|=1$. O resultado mostrou que algumas proposições (IE1, IC4, IE2, IE5, IC5, QC2, QE1, QE2, QE4 e QE5) obtiveram valores menores que um. Estas tiveram que ser eliminadas para que a análise do questionário continuasse.

Após a consistência interna dos itens, foi feita a medida de confiabilidade da escala; isto é, a validade de constructo, utilizando o coeficiente a de Cronbach, como afirma Pereira (1999). O software SPSS 17.x tem a função Reliability Analysis que possibilita a análise de confiabilidade de um instrumento de coleta, e o mesmo é obtido pela fórmula $\alpha=((\mathrm{Kcov})$ var) $/ 1+(\mathrm{K}-1) \operatorname{cov} / \mathrm{var}$ (1) em que $\mathrm{K}$ corresponde ao número de variáveis consideradas, cov, à média das covariâncias; e var, à média das variâncias.

O valor obtido do a de Cronbach para as proposições dessa pesquisa, foi de 0,881 . Tal indicador assume valores entre 0 e 1 e trabalha com a premissa de que as correlações entre os itens são positivas. De forma geral, considera-se que um bom valor do a seria 0,70 ou superior (obtido com uma amostra significativa), portanto a amostra considerada é confiável.

Após a análise e validação da confiabilidade do grupo de proposições do questionário destinadas à percepção dos gestores (22 proposições iniciais), foi possível obter-se o grau de aderência de cada grupo, ou seja, um índice percentual que reflete o nível de concordância dos gestores para essas questões. Quanto maior o índice, mais concordante é o respondente à determinada proposição ou a um grupo de proposições, conforme Wilder (1981). A fórmula geral é Gap=100-(100/ ((C/N) / $((\mathrm{D} / \mathrm{N})+1)))(2)$.

Davis (1976) colocou os graus de aderência (Gap) numa escala sequencial, que tem como limite superior 90\% (para uma concordância muito forte) ou mais e 
como limite inferior $9,99 \%$ ou menos (para uma discordância muito forte). Apresentase esta lista na Tabela 4, a seguir:

Tabela 4 - Interpretação do gap

\begin{tabular}{|c|c|}
\hline Valor do GAP & Frases adequadas \\
\hline $90 \%$ ou menos & Uma concordância muito forte \\
\hline $80 \%$ a $89,99 \%$ & Uma concordância substancial \\
\hline $70 \%$ a $79,99 \%$ & Uma concordância moderada \\
\hline $60 \%$ a $69,99 \%$ & Uma concordância baixa \\
\hline $50 \%$ a $59,99 \%$ & Uma concordância desprezível \\
\hline $40 \%$ a $49,99 \%$ & Uma discordância desprezível \\
\hline $30 \%$ a $39,99 \%$ & Uma discordância baixa \\
\hline $20 \%$ a $29,99 \%$ & Uma discordância moderada \\
\hline $10 \%$ a $19,99 \%$ & Uma discordância substancial \\
\hline $9,99 \%$ ou menos & Uma discordância muito forte \\
\hline
\end{tabular}

Fonte: Davis (1976), adaptado pelos autores da pesquisa

Nas Tabelas 5, 6, 7, e 8 têm-se os graus de aderência para IC, IE, QC e QE, respectivamente, calculados conforme a fórmula geral descrita, sendo: o grau de discordância (soma das respostas em DT e D) e o grau de concordância (soma das respostas em CT e C).

Tabela 5 - Grau de aderência para gestão operacional de inovação

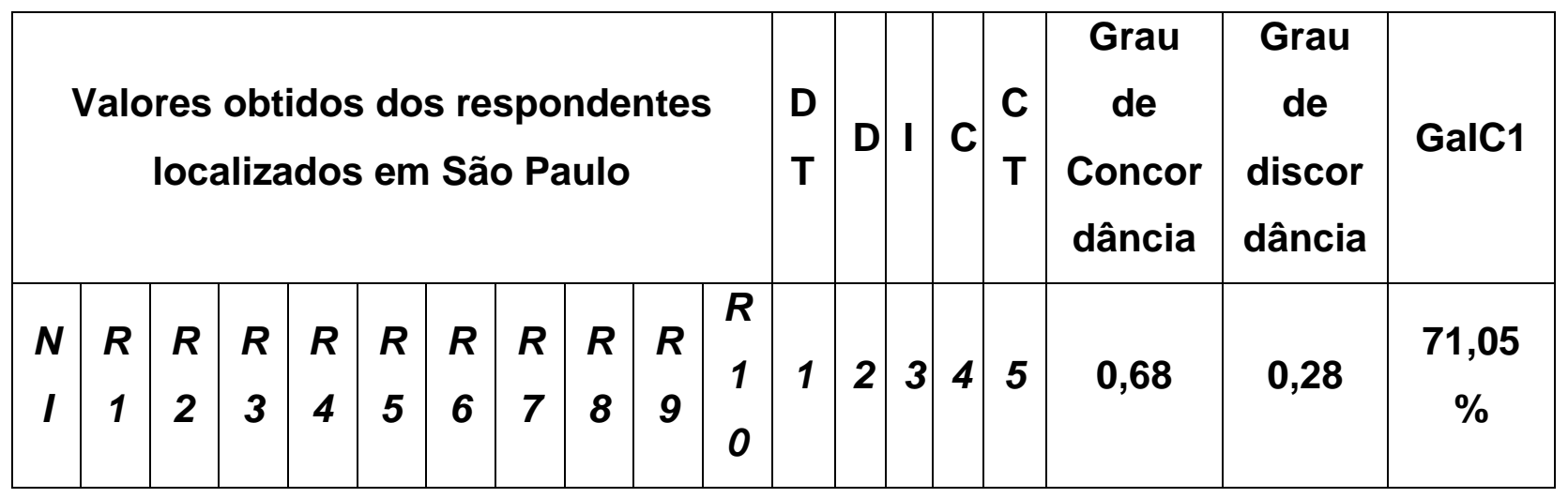




\begin{tabular}{|c|c|c|c|c|c|c|c|c|c|c|c|c|c|c|c|c|c|c|}
\hline $\begin{array}{l}\text { I } \\
\text { C } \\
1\end{array}$ & 4 & 4 & 3 & 4 & 2 & 4 & 5 & 2 & 5 & 4 & 0 & 2 & 1 & 5 & 2 & & & $\begin{array}{l}\text { concor } \\
\text { dância } \\
\text { moder }\end{array}$ \\
\hline $\begin{array}{l}C \\
2\end{array}$ & 1 & 2 & 2 & 3 & 2 & 2 & 2 & 4 & 4 & 4 & 0 & 1 & 1 & 4 & 4 & & & ada \\
\hline $\begin{array}{l}C \\
3\end{array}$ & 4 & 4 & 2 & 4 & 2 & 5 & 4 & 2 & 5 & 4 & 1 & 3 & 1 & 5 & 2 & & & \\
\hline $\begin{array}{l}C \\
6\end{array}$ & 2 & 4 & 4 & 2 & 2 & 5 & 4 & 2 & 4 & 2 & 0 & 5 & 0 & 4 & 1 & & & \\
\hline & $\begin{array}{l}\text { Valc } \\
\text { loc }\end{array}$ & $\begin{array}{r}\text { res } \\
\text { aliz } \\
\text { C }\end{array}$ & obt & o L & np & $\begin{array}{l}\text { re } \\
\text { tia }\end{array}$ & $\begin{array}{l}\text { Os } \\
\text { ulis }\end{array}$ & $\begin{array}{l}\text { ide } \\
\text { asce } \\
\text { ta }\end{array}$ & $\begin{array}{l}\text { htes } \\
\text { e }\end{array}$ & & $\begin{array}{l}\mathbf{D} \\
\mathbf{T}\end{array}$ & D & I & C & $\begin{array}{l}\mathbf{C} \\
\mathbf{T}\end{array}$ & $\begin{array}{c}\text { Grau } \\
\text { de } \\
\text { Concor } \\
\text { dância }\end{array}$ & $\begin{array}{c}\text { Grau } \\
\text { de } \\
\text { discor } \\
\text { dância }\end{array}$ & GalC2 \\
\hline $\begin{array}{c}N \\
I\end{array}$ & $\begin{array}{c}R \\
1 \\
1\end{array}$ & $\begin{array}{l}R \\
1 \\
2\end{array}$ & $\begin{array}{l}R \\
1 \\
3\end{array}$ & $\begin{array}{l}R \\
1 \\
4\end{array}$ & $\begin{array}{l}R \\
1 \\
5\end{array}$ & $\begin{array}{l}R \\
1 \\
6\end{array}$ & $\begin{array}{l}R \\
1 \\
7\end{array}$ & $\begin{array}{c}R \\
1 \\
8\end{array}$ & \begin{tabular}{c|}
$R$ \\
1 \\
9
\end{tabular} & $\begin{array}{l}R \\
2 \\
0\end{array}$ & 1 & 2 & 3 & 4 & 5 & \multirow{5}{*}{0,65} & \multirow{5}{*}{0,20} & \multirow{5}{*}{$\begin{array}{c}76,47 \\
\% \\
\text { concor } \\
\text { dância } \\
\text { moder } \\
\text { ada }\end{array}$} \\
\hline $\begin{array}{l}\text { I } \\
\text { C }\end{array}$ & 4 & 2 & 4 & 4 & 4 & 5 & 4 & 4 & 3 & 4 & 0 & 1 & 1 & 7 & 1 & & & \\
\hline $\begin{array}{l}C \\
2\end{array}$ & 1 & 2 & 2 & 4 & 2 & 1 & 2 & 3 & 2 & 1 & 0 & 1 & 1 & 4 & 4 & & & \\
\hline 3 & 4 & 2 & 3 & 3 & 5 & 5 & 3 & 2 & 4 & 4 & 0 & 2 & 3 & 3 & 2 & & & \\
\hline 6 & 4 & 1 & 2 & 2 & 1 & 4 & 4 & 5 & 3 & 4 & 2 & 2 & 1 & 4 & 1 & & & \\
\hline
\end{tabular}


Fonte: Autores (2017)

Legenda: $\mathrm{NI}$ : número interno da proposição. V: variável. P: número da proposição. N: número de respondentes vezes o número de proposições consideradas. DT, D, I, C, CT: diferencial semântico. Grau de Concordância=soma das respostas C e CT. Grau de discordância=soma das respostas D e DT. GalC1 e GalC2: Grau de aderência para gestão operacional de inovação.

Tabela 6 - Grau de aderência para gestão estratégica de inovação

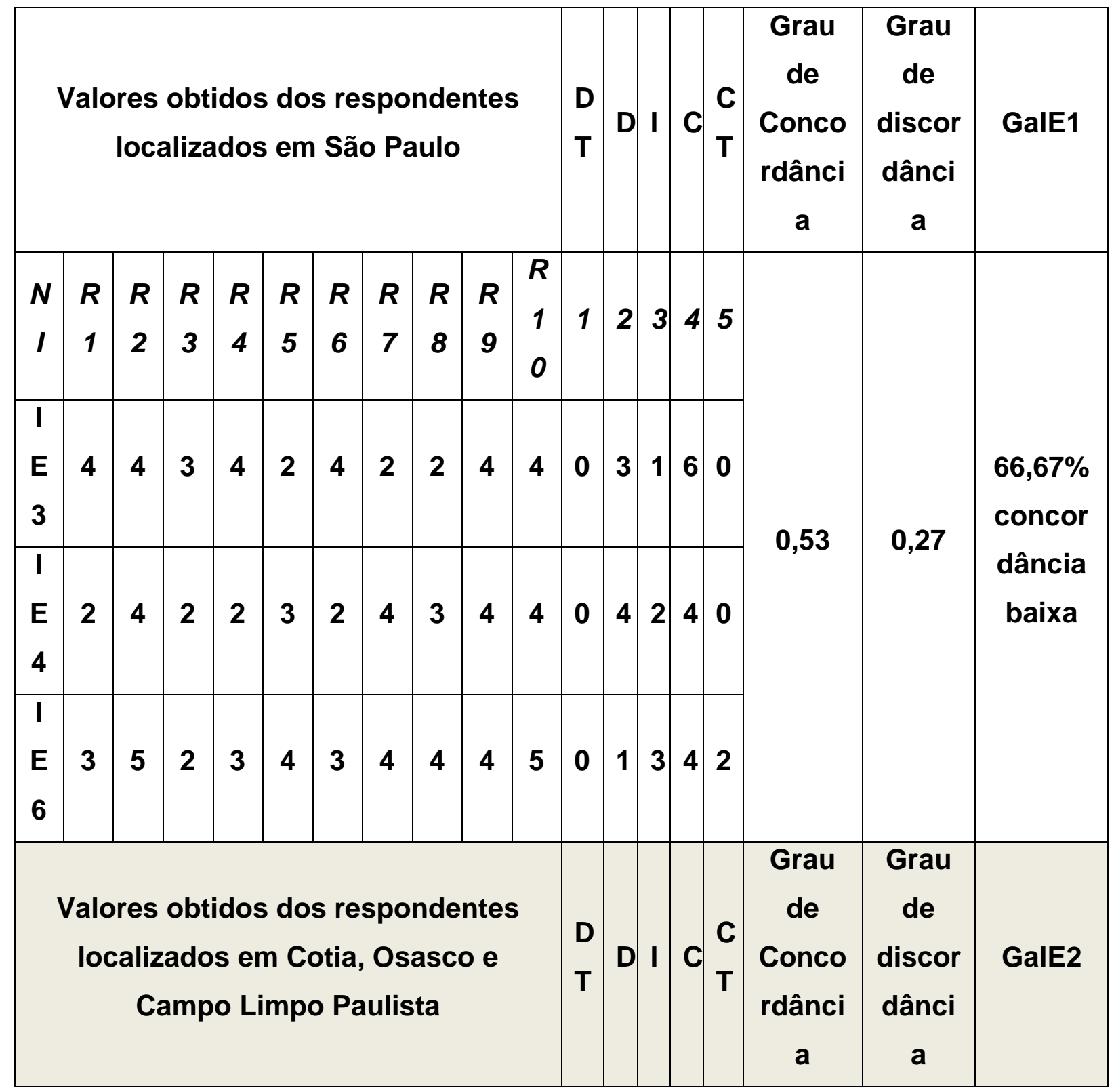




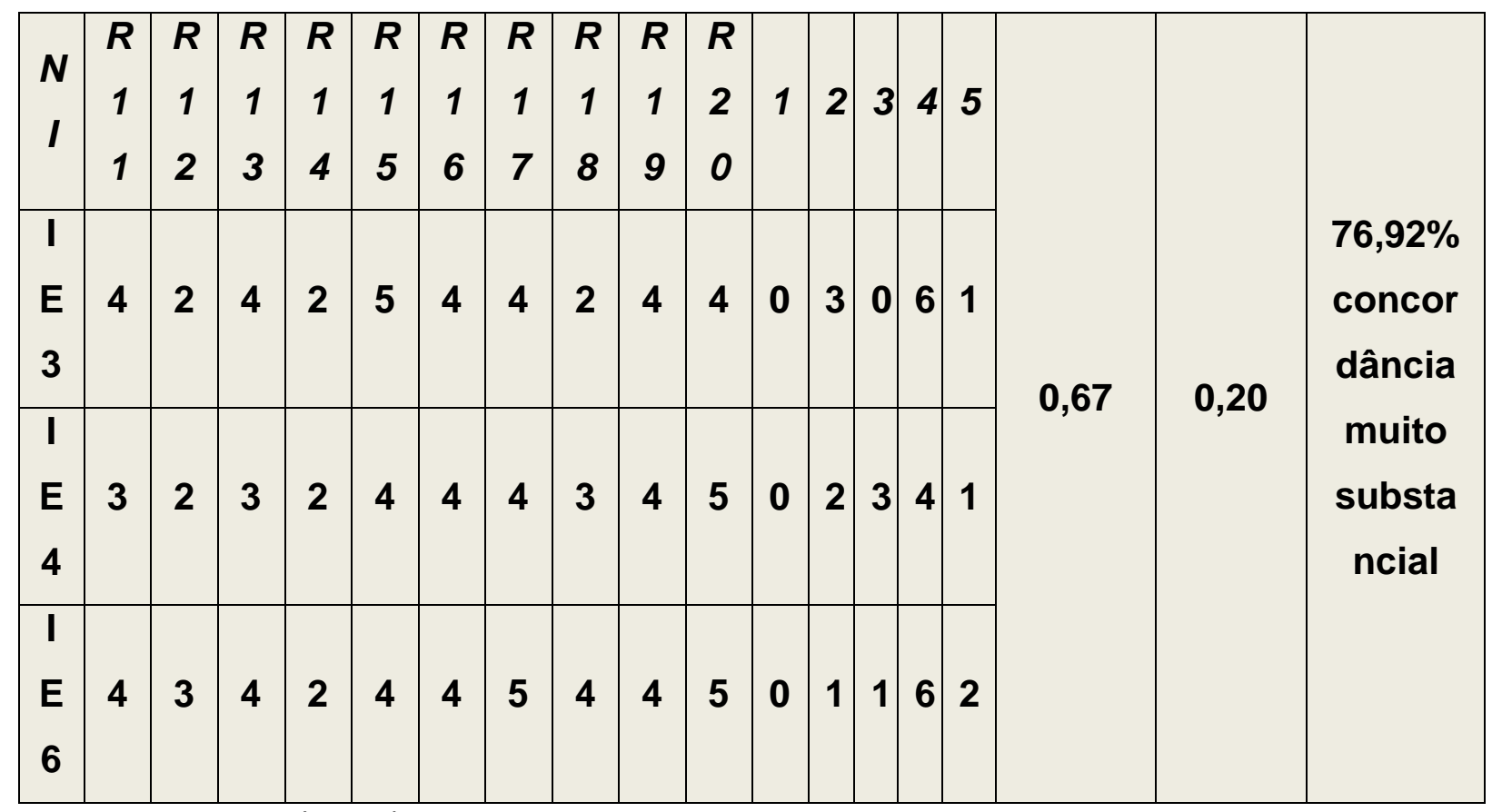

Fonte: Autores (2017)

Legenda: NI: número interno da proposição. V: variável. P: número da proposição. N: número de respondentes vezes o número de proposições consideradas. DT, D, I, C, CT: diferencial semântico. Grau de Concordância=soma das respostas C e CT. Grau de discordância=soma das respostas D e DT. GalE1 e GalE2: Grau de aderência para gestão estratégica de inovação.

Tabela 7 - Grau de aderência para gestão operacional da qualidade

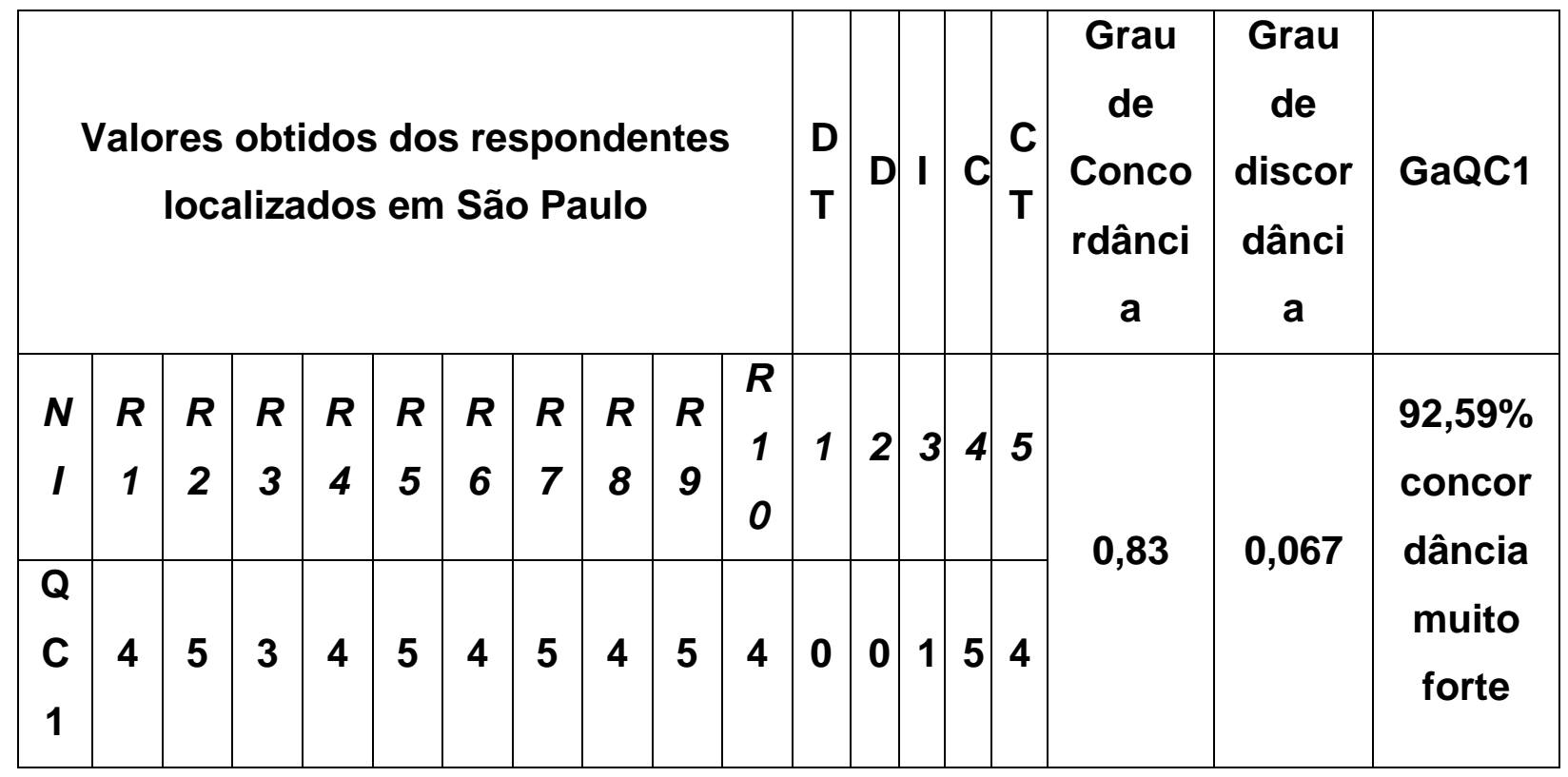




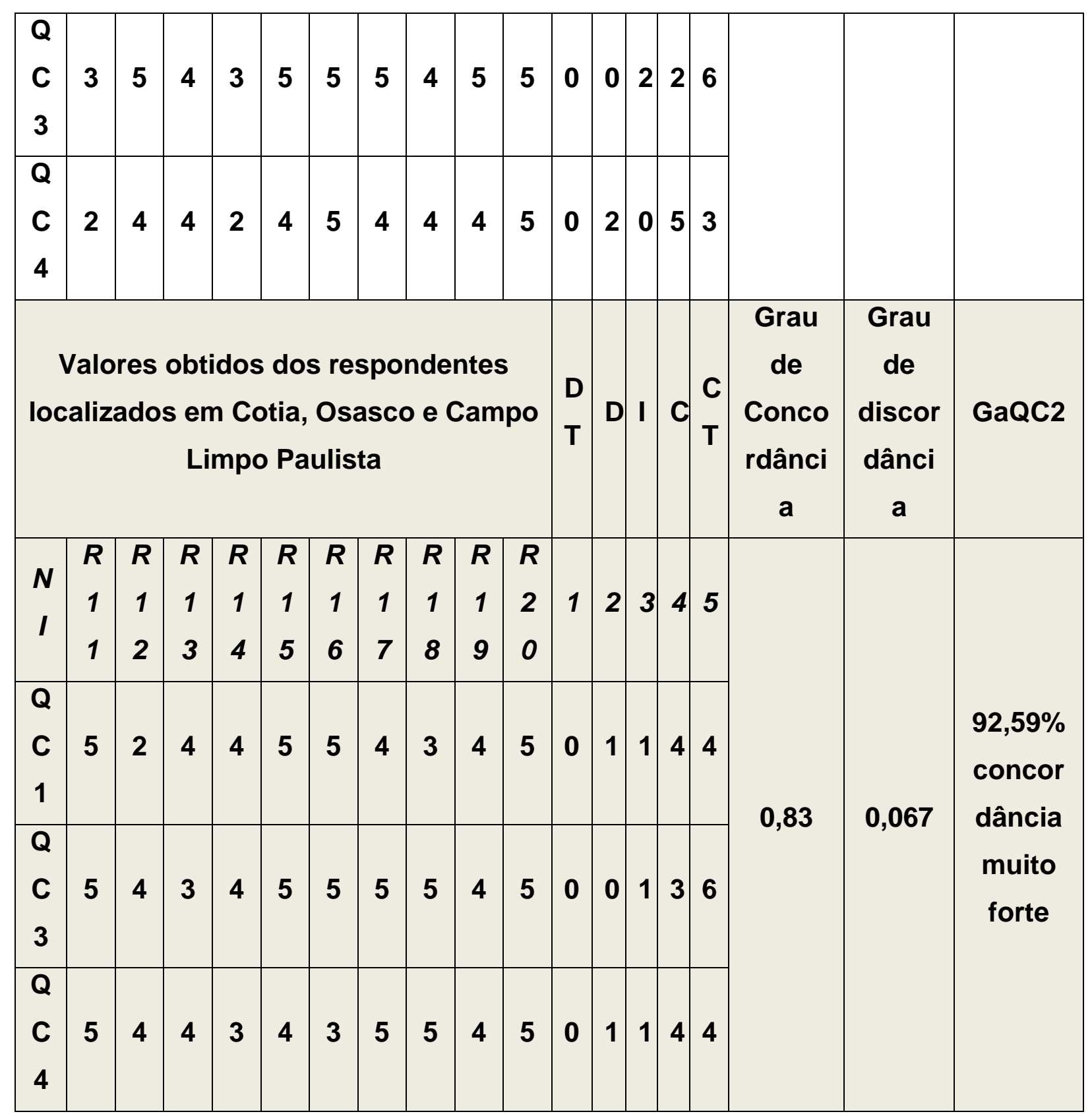

Fonte: Autores (2017)

Legenda: NI: número interno da proposição. V: variável. P: número da proposição. N: número de respondentes vezes o número de proposições consideradas. DT, D, I, C, CT: diferencial semântico. Grau de Concordância=soma das respostas C e CT. Grau de discordância=soma das respostas D e DT; GaQC1 e GaQC2: Grau de aderência para gestão operacional da qualidade. 
Tabela 8 - Grau de aderência para gestão estratégica de qualidade

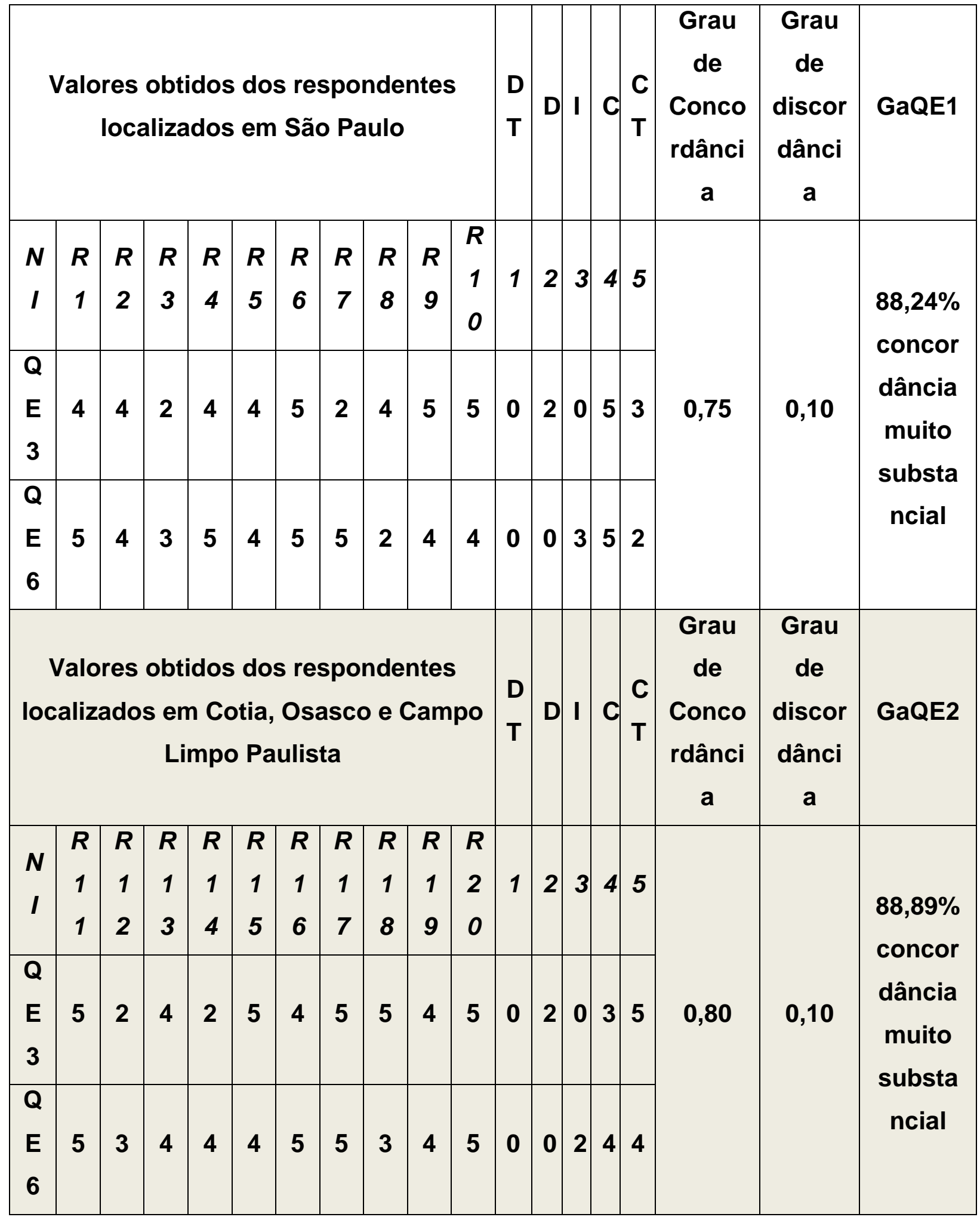

Fonte: Autores (2017)

Legenda: NI: número interno da proposição. V: variável. P: número da proposição. N: número de respondentes vezes o número de proposições consideradas. DT, D, I, C, Revista Inova Saúde, Criciúma, vol. 10, n. 2, jul. 2020. 
CT: diferencial semântico. Grau de Concordância=soma das respostas C e CT. Grau de discordância=soma das respostas D e DT; GaQE1 e GaQE2: Grau de aderência para gestão operacional da qualidade.

Tabela 9 - Porcentagem de concordância para as proposições individuais

\begin{tabular}{|c|c|c|c|}
\hline NI & Proposição & $\begin{array}{l}\text { Concordância para } \\
\text { os respondentes de } \\
\text { São Paulo }\end{array}$ & $\begin{array}{l}\text { Concordância para } \\
\text { os respondentes de } \\
\text { Cotia, Osasco e } \\
\text { Campo Limpo } \\
\text { Paulista }\end{array}$ \\
\hline IC1 & $\begin{array}{l}\text { Na sua empresa os colaboradores possuem suas atividades bem } \\
\text { definidas e estabelecidas por normas. }\end{array}$ & $70 \%$ & $80 \%$ \\
\hline IC2 & $\begin{array}{l}\text { Na sua empresa os colaboradores têm a necessidade de compreender } \\
\text { quais são os exames e diagnóstivos oferecidos pela empresa para os } \\
\text { clientes. }\end{array}$ & $80 \%$ & $80 \%$ \\
\hline IC3 & $\begin{array}{l}\text { Na sua empresa os colaboradores expõem com clareza para os } \\
\text { clientes os objetivos e as diretrizes da empresa. }\end{array}$ & $80 \%$ & $80 \%$ \\
\hline IC6 & $\begin{array}{l}\text { Na sua empresa os colaboradores se sentem a vontade para falar, } \\
\text { criticar, sugerir, trocar informações }\end{array}$ & $80 \%$ & $80 \%$ \\
\hline IE3 & $\begin{array}{l}\text { A sua empresa sente a necessidade de promover capacitação para } \\
\text { desenvolvimento dos gestores. }\end{array}$ & $60 \%$ & $70 \%$ \\
\hline IE4 & $\begin{array}{l}\text { A sua empresa executa mudanças necessárias na estrutura para } \\
\text { estimular novas ideias, facilitando a tomada de decisão. }\end{array}$ & $40 \%$ & $40 \%$ \\
\hline IE6 & $\begin{array}{l}\text { Na sua empresa comparam-se sistematicamente seus produtos e } \\
\text { serviços com de outras empresas do ramo. }\end{array}$ & $80 \%$ & $80 \%$ \\
\hline QC1 & $\begin{array}{l}\text { Na sua empresa os colaboradores se empenham em tratar bem os } \\
\text { cliente. }\end{array}$ & $90 \%$ & $80 \%$ \\
\hline QC3 & $\begin{array}{l}\text { Na sua empresa os colaboradores têm um pensamento único, que se } \\
\text { está trabalhando com vidas humanas e isto requer antes de tudo muita } \\
\text { calma, profissionalismo e o máximo de confiança dos clientes. }\end{array}$ & $90 \%$ & $80 \%$ \\
\hline QC4 & $\begin{array}{l}\text { Na sua empresa os colaboradores prestam atenção para que os } \\
\text { clientes sejam bem tratados }\end{array}$ & $80 \%$ & $80 \%$ \\
\hline QE3 & $\begin{array}{l}\text { A sua empresa está falando a verdade quando diz que o cliente está em } \\
\text { primeiro lugar. }\end{array}$ & $80 \%$ & $80 \%$ \\
\hline QE6 & $\begin{array}{l}\text { a sua empresa realiza constantemente pesquisa, junto aos clientes } \\
\text { finais e revendedores para conhecer a qualidade dos seus produtos e } \\
\text { serviços. }\end{array}$ & $80 \%$ & $80 \%$ \\
\hline
\end{tabular}

Fonte: Autores (2017)

Legenda: NI: número interno da proposição.

\section{CONCLUSÃO}

$\mathrm{Na}$ percepção dos gestores das empresas prestadoras de serviços pesquisadas, a gestão estratégica de inovação praticada pelos executivos era positiva e não diferiu muito da gestão operacional de inovação executada pelos colaboradores. Havia na percepção desses, um plano de inovação elaborado e definido pelas organizações, sendo que ele era bem executado pelos colaboradores, que não têm função de gestão.

Revista Inova Saúde, Criciúma, vol. 10, n. 2, jul. 2020.

ISSN 2317-2460 
Pode-se afirmar que as empresas pesquisadas, apesar de terem sofrido pressão direta da concorrência na região onde estavam localizadas, ainda se mantinham no mercado, obedecendo à linha de pensamento neoschumpeteriano (firmas que investem mais em gestão de inovação vão sobreviver em detrimento da 'morte' das que não investem; Meirelles, 1989). A evidência desse fato é que, apesar de as empresas pesquisadas terem como concorrentes grandes laboratórios de análises clínicas, ainda continuavam se mantendo no mercado.

Pode-se demonstrar que, na percepção dos gestores localizados em São Paulo, a gestão estratégica de inovação, aquela praticada pelos executivos das empresas pesquisadas, diferia da percepção de gestão operacional de inovação, que era praticada pelos colaboradores que não tinham função de gestão. Conclui-se que não existia na percepção desses gestores um plano bem definido de gestão de inovação gerado pelos executivos dessas empresas. Contudo, o mínimo de gestão de inovação passado e divulgado para os outros colaboradores, que não tinham função de gestão, era bem executado por estes. Para os gestores localizados fora da cidade de São Paulo, não existia diferença nessa percepção.

Essa conclusão corrobora e complementa uma das conclusões da pesquisa de Pereira (2012), que afirma que geralmente essas organizações não possuem como práticas organizacionais a formalização da estratégia. Como evidência desse fato, temos que o resultado para o grau de aderência para as perguntas feitas para detectar a percepção da gestão estratégica de inovação foi de uma concordância baixa, ou seja, menos de $70 \%$ de concordância, enquanto o grau de aderência de percepção para a gestão operacional, ou seja, a execução das práticas de inovação foi de uma concordância moderada, acima de $70 \%$.

Com relação à questão de a empresa promover capacitação técnica para desenvolvimentos dos seus profissionais, pode-se concluir que o resultado obtido está de acordo com a colocação de Grönroos (2003), que afirma que qualidade na prestação de serviços está diretamente relacionada à capacidade técnica e à formação profissional dos funcionários em seus diversos níveis de atendimento. Além disso, atende a proposição de Espuny (2008), que afirma que as pessoas são os principais responsáveis pelo processo de qualidade. Para que isso aconteça, é 
necessário efetuar treinamentos, ou seja, é importante que os gestores se preocupem em investir em treinamentos para os funcionários.

Analisando-se as colocações de que os colaboradores se empenham em tratar bem os clientes, pelo que foi obtido de retorno das respostas dos gestores pesquisados (90\% de concordância para os que se localizam em São Paulo e 80\% para os que se localizam fora da cidade de São Paulo), verifica-se que estão alinhadas com as colocações de Albrecht (2000), que enfatiza a importância de considerar-se o momento de contato com a clientela como o principal fator de qualquer esforço mercadológico. Ou seja, o momento quando o cliente entra em contato com algum aspecto da organização e obtém impressão de qualidade de seus serviços. Esta é reforçada com a colocação de Davel e Melo (2005), que afirmam que a preocupação com 0 atendimento com qualidade estabelece valores diferenciais e agrega valor competitivo à empresa.

\section{REFERÊNCIAS}

1. Schumpeter JA. Capitalism, socialism and democracy. New York \& London: Harper \& Row, 1950. $431 \mathrm{p}$.

2. Davila T, Epstein MJ, Shelton R. As regras da inovação. Porto Alegre: Bookman, 2007. $336 \mathrm{p}$.

3. Pohlmann M. The evolution of innovation: cultural backgrounds and the use of innovation models. Technol Anal Strateg Manag. 2005;17(1):9-19.

4. Rosenbusch N, Brinckmann J, Bausch A. Is innovation always beneficial? A metaanalysis of the relationship between innovation and performance in SMEs. $J$ Bus Ventur. 2011;26(4):441-57.

5. Fuentes MMF, Montes FJL, \& Fernández, LMM. Total quality management, strategic orientation and organizational performance: the case of Spanish companies. Total Quality Management \& Business Excellence. 2006;17(3),303-23.

6. Han SB, Chen SK, Ebrahimpour M. The impact of ISO 9000 on TQM and business performance. The Journal of Business and Economic Studies. 2007;13(2):1-25.

7. Lenka $U$, Suar D. A holistic model of total quality management in services. The Icfaian Journal of Management Research. 2008;7(3),56-72. 
8. Fernandes A, Lourenço L, Silva MJ. Exploring the synergy between total quality management and innovation. In ECEI2011-6th European Conference on Innovation and Entrepreneurship: ECEI 2011 (p. 278). Academic Conferences Limited.

9. Solla J, Chioro A. Atenção ambulatorial especializada. In: Giovanella L, Escorel S, et al. Políticas e sistema de saúde no Brasil. Rio de Janeiro: Fiocruz; 2012.

10. Schumpeter JA. Teoria do desenvolvimento econômico: uma investigação sobre lucros, capital, crédito, juro e o ciclo econômico. São Paulo: Nova Cultural, 1934. 239 p.

11. Tavares PV, Kretzer J, Medeiros N. Economia neoschumpeteriana: expoentes evolucionários e desafios endógenos da indústria brasileira. Revista Economia Ensaios. 2005;20(1),127-55.

12. Serafim L. O poder da inovação: como alavancar a inovação na sua empresa. São Paulo: Saraiva, 2011. 237 p.

13. Tidd J, Bessant J. Gestão da inovação. Porto Alegre: Bookman, 2015. 648 p.

14. Tigre PB. Gestão da Inovação: Uma abordagem estratégica, organizacional e de gestão de conhecimento. Rio de Janeiro: Elsevier, 2014. 441 p.

15. de Oslo OM. Diretrizes para coleta e interpretação de dados sobre inovação. Paris: Organização para a Cooperação e Desenvolvimento Econômico, 2005. 184 p.

16. lacono A, Nagano MS. Gestão da inovação em empresas nascentes de base tecnológica: evidências em uma incubadora de empresas no Brasil. Revista Interciência. 2014;39(5),296-306.

17. Kuczmarski TD. Por uma consciência inovadora. HSM Management. 1998;5(1),628.

18. Gianesi I, Corrêa H. Administração estratégica de serviços. São Paulo: Atlas, 2009. $312 \mathrm{p}$.

19. Espuny HG. O que é qualidade. Adm [internet]. 2008 [acesso em 2013 Aug 31]: [aproximadamente 1p.]. Disponível em: http://www.administradores.com.br/artigos/negocios/o-que-e-qualidade/23926/.

20. Barras R. Interactive innovation in financial and business services: the vanguard of the service revolution. Research Policy. 1990;19(3),215-237. 
21. Gallouj F. Economia da inovação: um balanço dos debates recentes. In Bernardes RC, Andreassi T. Inovação em Serviços Intensivos em Conhecimento. São Paulo: Saraiva; 2007. p.3-27.

22. Filho JM. Planejamento e gestão estratégica em organizações de saúde. Rio de Janeiro: FGV, 2010. 152 p.

23. Seki M, Júnior PGP, Seki MO, Niyama FP, Caruso MC, Paschoaletto MCDL, Seki MO, Sellmann SAS, Vivan RHF, Ruiz LP. A inovação de valores nos laboratórios clínicos. J Bras Patol Med Lab. 2003;39(3),211-4.

24. Bossuyt $\mathrm{X}$, Verweire $\mathrm{K}$, Blanckaert $\mathrm{N}$. Laboratory medicine: challenges and opportunities. Clinical Chemistry. 2007;53(10),1730-3.

25. Blumenthal D. The errors of our ways. Clinical Chemistry. 1997;43(8),1305-05.

26. Gryna FM, Juran JM, Seder LA. Quality control handbook. New York: McGraw-Hill, 1962. $992 \mathrm{p}$.

27. Ishikawa K. TQC, Total Quality Control: estratégia e administração da qualidade. São Paulo: IMC Internacional Sistemas Educativos, 1986. 220 p.

28. Davel E, Melo MCO. Gerência em ação: singularidades e transformações no trabalho dos gerentes. Rio de Janeiro: FGV, 2005. 338 p.

29. Harvey J. Service quality: a tutorial. Journal of Operations Management. 1998;16(5),583-97.

30. Deming EW. Qualidade: a revolução da administração. Rio de Janeiro: Marques Saraiva, 1990. 367 p.

31. Pasquali RC. Metodologia para melhoria de processos de linha de frente em serviços: aplicação em laboratório de análises clínicas. [Dissertação]. [Florianópolis]: Universidade Federal de Santa Catarina; 2002. 139 p.

32. Donabedian A. The quality of medical care. Science. 1978;200(4344),856-64.

33. Bonato VL. Gestão de qualidade em saúde: melhorando assistência ao cliente. $O$ Mundo da Saúde. 2011;35(5),319-31.

34. Creswell J. Projeto de pesquisa: métodos qualitativo, quantitativo e misto. Porto Alegre: Bookman, 2007. 296p.

35. Baquero G. Testes psicométricos e projetivos. São Paulo: Loyola, 1974. 233 p.

36. Pereira JCR. Análise de dados qualitativos: estratégias metodológicas para as ciências da saúde, humanas e sociais. São Paulo: Edusp, 1999. 156 p. 
37. Wilder RL. Mathematics as a cultural system. Oxford, UK: Pergamon Press, 1981. $194 \mathrm{p}$.

38. Davis J. Levantamento de dados em sociologia. Rio de Janeiro: Zahar, 1976. 239 p.

39. Meirelles JGP. Tecnologia, transformação industrial e comercio internacional: uma revisão das contribuições neoshumpeterianas, com particular referência às economias da América Latina. [Dissertação]. [Campinas]: IE-UNICAMP; 1989. 228 p. 40. Pereira FMF. Fatores responsáveis pela mudança no desempenho da indústria das análises clínicas no Brasil. [Dissertação]. [Rio de Janeiro]: Escola Brasileira de Administração Pública e de Empresas; 2012. 129 p.

41. Grönroos C. Marketing, gerenciamento e serviços. Rio de Janeiro: Campus, 2003. $377 \mathrm{p}$.

42. Albrecht K. Revolução nos serviços: como as empresas podem revolucionar a maneira de tratar os seus clientes. São Paulo: Pioneira, 2000. 254p. 